This item was submitted to Loughborough's Research Repository by the author.

Items in Figshare are protected by copyright, with all rights reserved, unless otherwise indicated.

\title{
Maternal short stature does not predict their children's fatness indicators in a nutritional dual-burden sample of urban Mexican Maya
}

PLEASE CITE THE PUBLISHED VERSION

http://dx.doi.org/10.1002/ajpa.22463

PUBLISHER

(c) Wiley Periodicals, Inc.

VERSION

SMUR (Submitted Manuscript Under Review)

LICENCE

CC BY-NC-ND 4.0

\section{REPOSITORY RECORD}

Wilson, Hannah J., Federico Dickinson, Paula L. Griffiths, Barry Bogin, Matthew Hobbs, and Maria Ines Varela Silva. 2019. "Maternal Short Stature Does Not Predict Their Children's Fatness Indicators in a Nutritional Dualburden Sample of Urban Mexican Maya". figshare. https://hdl.handle.net/2134/14008. 
This item was submitted to Loughborough's Institutional Repository (https://dspace.lboro.ac.uk/) by the author and is made available under the following Creative Commons Licence conditions.

\section{creative
commons}

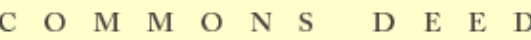

Attribution-NonCommercial-NoDerivs 2.5

You are free:

- to copy, distribute, display, and perform the work

Under the following conditions:

Attribution. You must attribute the work in the manner specified b the author or licensor.

Noncommercial. You may not use this work for commercial purposes.

No Derivative Works. You may not alter, transform, or build upon this work.

- For any reuse or distribution, you must make clear to others the license terms of this work.

- Any of these conditions can be waived if you get permission from the copyright holder.

Your fair use and other rights are in no way affected by the above.

This is a human-readable summary of the Leqal Code (the full license).

\section{Disclaimer 만}

For the full text of this licence, please go to: http://creativecommons.org/licenses/by-nc-nd/2.5/ 
1

2

3

4

\section{Abstract}

6 Objective: The co-existence of very short stature due to poor chronic environment in early life

7 and obesity is becoming a public health concern in rapidly transitioning populations with high

\section{Title}

Maternal short stature does not predict their children's adiposity indicators in a nutritional dualburden sample of urban Mexican Maya obesity in times of relative caloric abundance. Increasing evidence shows that an individual is influenced by exposures in previous generations. This study assesses whether maternal poor early life environment predicts her child’s adiposity.

Design: A cross sectional study comparing maternal chronic early life environment (stature) with her child’s adiposity (body mass index (BMI) z-score, waist circumference z-score and percentage body fat) using multiple linear regression, controlling for the child's own environmental exposures (household sanitation and maternal parity).

Setting: The south of Merida, Yucatan, Mexico, a low socioeconomic urban area in an upper middle income country.

Subjects: Maya schoolchildren aged 7-9 and their mothers ( $\mathrm{n}=57$ pairs).

Results: The Maya mothers were very short, with a mean stature of $147 \mathrm{~cm}$. The children had fairly high adiposity levels, with BMI and waist circumference z-scores above the reference median. Maternal stature did not significantly predict any child adiposity indicator.

Conclusions: There does not appear to be an intergenerational component of maternal early life chronic under-nutrition on her child's obesity risk within this free living population living in poverty. These results suggest that the co-existence of very short stature and obesity appears to be primarily due to exposures and experiences within a generation rather than across generations. 
2 The burden of disease in developing countries has been shifting in the last decades from a profile 3 dominated by diseases of under-nutrition and infection to nutrition-related, non-communicable

4 diseases such as cardiovascular disease. Some populations undergo this transition within a

5 generation and many do not eliminate the issues related to poverty ${ }^{(1)}$.

6 Within this context, a great percentage of individuals who experienced chronically poor nutrition

7 in their early lives, and are thus stunted, seem to be more predisposed to obesity later in life ${ }^{(2-10)}$.

8 Individuals with chronic under-nutrition (stunting) in early life seem to have reduced energetic

9 demands through metabolic ${ }^{(6,9,11-13)}$ and behavioural shifts ${ }^{(14-16)}$. Such reduced energetic

10 demands may increase an individual's odds of immediate survival under conditions of energetic

11 stress yet have negative longer-term consequences in health and survival. This seems to be the

12 case in situations in which rapid nutrition transition is coupled with high rates of poverty where

13 calories rapidly become more abundant and lifestyles become more mechanized. Stunted

14 individuals predisposed to energy conservation may be at an increased risk of obesity when calories are relatively abundant and energy expenditure requirements are low.

The implications of the energy conservation effects of chronic early life under-nutrition may extend into future generations. It is theoretically possible for mothers to transfer energetic strategies to their children ${ }^{(17-21)}$. In theory, a child born of a stunted mother is more likely to be predisposed to energy conservation than a child whose mother was not stunted. This predisposition may increase the child's risk of excess adiposity. Such intergenerational effects are a consequence of ancestral phenotypes, results of past socioeconomic, cultural, and political conditions, biologically expressed as epigenetic modifications to DNA, but are not mediated by inherited DNA sequences $^{(22)}$. The majority of research into intergenerational influences has

24 focused on exposure during gestation, mainly conducted in rats ${ }^{(22-24)}$. A classic example of the 25 intergenerational effects in humans can be seen in the studies reporting on the Dutch Winter 26 Famine $^{(26)}$. In these studies, the authors examined the effects of six months of severe wartime 27 rationing (November 1944-May 1945) in the Netherlands. Individuals exposed to the rationing in utero had children with higher ponderal indices at birth than those unexposed or exposed postnatally. These results suggest that calorie restriction during gestation causes an intergenerational predisposition to the activation of energy conservation mechanisms. 
However the majority of under-nutrition in the world today is not due to a single acute event, such as severe wartime rationing, but is chronic and linked to persistent poverty and food insecurity ${ }^{(27)}$. It is unknown at this point whether chronic under-nutrition, particularly postnatally, in one generation increases the risk for obesity in future generations. Persistent negative conditions have been found to influence the risk of non-communicable, chronic diseases, such as cardiovascular diseases. For example, the history of slavery and systematic marginalization has been linked to the disproportionate cardiovascular disease burden of African Americans in the United States $^{(28)}$. African Americans also have the highest rates of adult obesity in the United States ${ }^{(29)}$. Since obesity is a precursor to cardiovascular disease and other non-communicable diseases $^{(30,31)}$, it is may be possible for obesity to be affected by an intergenerational legacy as well.

Household dual burden involving a stunted mother and an overweight or obese child is a phenomenon linked to rapid nutrition transition and poverty. This household dual burden phenomenon offers an opportunity to investigate intergenerational influences of chronic nutritional stress on obesity risk in humans. The mothers who are stunted experienced early life chronic under-nutrition, primarily before the age of $5^{(32)}$. Since stunting is so closely linked to poverty and food insecurity, it is likely that the chronic under-nutrition that led to shorter stature in these women but was persistent within their families before and after they were conceived. This is a particularly strong assumption if a sample is drawn from a population with a long history of systematic marginalization and under-nutrition, such as many indigenous Americans groups including the Maya ${ }^{(33)}$. Within this context, we can assume that adult women who are stunted were exposed to under-nutrition in utero as well as post-natally, which would program their own metabolism for energy conservation as well as their gametocytes. Therefore, it is possible that stunted mothers pass along a predisposition for energy conservation to their children $^{(3,20,34-36)}$. Such children would be predisposed to have high levels of adiposity and be at increased risk of obesity.

The aim of this study is to determine whether maternal chronic under-nutrition in early life, as measured by mother's adult stature, has an intergenerational influence on the adiposity of their 79 year old Maya children. Within this age range growth is fairly stable ${ }^{(37)}$ and adiposity is 
1 predictive of later life fatness, health risks ${ }^{(38)}$. We aim to determine whether Maya mothers who experienced chronically poor early life conditions (and are therefore very short) convey an increased risk for greater fatness to their children. The null hypotheses being tested are that maternal stature will not significantly predict: 1) child's body mass index (BMI-for-age z-score); 2) child's percentage of body fat (\%BF); and 3) child's waist circumference (WC-for-age zscores) after controlling for the children's own environmental exposures.

\section{Experimental Methods}

9 Cross-sectional data were collected, between March and July 2010, on 58 Maya mothers and their children (aged 7.00 to 9.99 years), living in the south of Merida, Yucatan, Mexico.

\section{Study population and location}

12 The Maya are the largest indigenous group in the Americas, with a population of 7-8 million ${ }^{(39)}$. 13 Similar to other Amerindian populations, the Maya experienced systematic marginalization for 14 centuries. Within Mexico, the official marginalization policies have ended but the Maya people 15 remain one of the poorest ethnic groups in the country ${ }^{(40)}$ and have high rates of stunting ${ }^{(41,42)}$. Between 1500 and the late $20^{\text {th }}$ century A.D., the Maya economy in Yucatan, Mexico was based 17 upon subsistence agriculture, particularly of maize. The Maya also worked as near slaves in the regional agroindustries. Since the late 1970's and 1980's, Yucatecan Maya have migrated to urban and coastal areas in search of employment in construction and tourism related industries, or other low-skilled work. The diets of the Maya in the Yucatan are increasingly dominated by calorie-dense, nutrient-poor foods ${ }^{(43,44)}$. The Maya in Merida are a dual burdened population, with high levels of stunting and overweight and obesity $(\mathrm{OW} / \mathrm{OB})^{(41,42)}$.

23 This study focuses on an urban population of Maya living in the south of Merida, Yucatan, 24 Mexico. Mexico is undergoing nutrition transition ${ }^{(45,46)}$. Merida is a rapidly growing city, home 25 to approximately 75,000 Maya speakers in 2010, roughly $9 \%$ of the city’s population ${ }^{(47)}$. Merida 26 is highly segregated from north to -south in terms of wealth, infrastructure and services ${ }^{(48,49)}$.

27 The south of the city has few services and is physically separated from the rest of the city by an 28 airport runway that makes leaving the south time consuming. While the south is a low income 
1 area, Mexico has implemented many public health measures in the past 30 years, including

2 vaccinations and clean drinking water campaigns ${ }^{(50,51)}$. Thus the south of Merida is a low

3 socioeconomic status area within an upper middle income country ${ }^{(52)}$ that is meeting some of the

4 basic requirements for child welfare ${ }^{(53)}$.

\section{$5 \quad$ Recruitment and ethics}

6 This study was conducted according to the guidelines laid down in the Declaration of Helsinki

7 and all procedures involving human subjects were approved by the [name of the ethics

8 committee removed for blinding]. Written informed consent was obtained from the mothers or

9 head of the household and verbal assent from the children. Prior to parental consent given for

10 study participation, the researchers had no contact with the children.

11 Recruitment took place in schools in the south of Merida, where a high proportion of Maya

12 reside. Mexico has official school enrolment rates of almost $100 \%{ }^{(51)}$ and therefore schools were

13 targeted for recruitment. Children with two Maya surnames (one from the father and mother)

14 between the ages of 7 and 9 years old were identified using school records. School directors

15 invited the mothers of identified children to group information sessions held at the school using

16 flyers. The study nature and requirements were verbally explained to the parents and information

17 sheets were given out during the information sessions. Spanish was used for all stages of

18 participant interaction because it is the dominant language of the south of Merida and all mothers

19 were comfortable speaking it.

21 Data collection

22 Anthropometry

23 Stature, weight, waist circumference (WC) and skinfolds (triceps and subscapular) were 24 measured using standard techniques ${ }^{(54)}$ on children and mothers. 
2 To assess body composition, bioelectrical impedance analysis (BIA) was measured (BioScan

3 916, Maltron, UK) on children and mothers and used to calculate percentage of body fat.

$5 \quad$ Interview

6 To assess family socioeconomic status, demographics and child's health, the researchers created

7 an interview based upon the most recent Mexican Demographic Health Survey (1987) ${ }^{(55)}$ and

8 piloted it in the south of Merida. Mothers were interviewed in the family home or school by

9 native Yucatec-Spanish speaking women. Mothers were asked their own and their child's dates

10 of birth. Parity was assessed by asking the mothers how many times they had given birth and

11 how many children they had. These two were perfectly correlated and used as the indicator of

12 maternal parity. Sanitation was assessed by asking whether the family owned a flush toilet, the

13 source of drinking water and method of cleaning drinking water. To assess socioeconomic status,

14 mothers were asked if the family owned the following consumer durable goods: radio, telephone,

15 refrigerator, car, tricycle or bicycle and a television.

16 Child's birth weight was assessed using maternal recall. When possible, the child's birth

17 certificate was obtained but only four mothers had it available. Within these cases, three of the

18 mothers recalled the birth weights higher than the weight recorded on the birth certificate,

19 indicating that there may be a systematic bias in this variable. For this reason, child's birth

20 weight was not included in the main statistical analysis.

22 Data analysis

23 Anthropometry

24 Body mass index (BMI) was calculated for mothers and children by dividing an individual's

25 weight in kilograms by the square of their stature in meters. Children's age- and sex- specific z-

26 scores were calculated for height, weight, BMI and WC using the Comprehensive reference

27 charts $^{(56)}$. The Comprehensive reference was created using data from a U.S. national, stratified 
1 sample that over-sampled minorities (NHANES III). The sample contains 27.0\% Hispanic and

2 Latinos (mostly Mexicans and Cubans). The Comprehensive reference is the largest sampled,

3 statistically validated growth reference that includes Mexican children.

4 Maternal stunting was defined as $150 \mathrm{~cm}^{(41,42,57)}$. Children were classified as OW/OB using the 5 International Obesity Task Force cut-offs for $\mathrm{BMI}^{(58)}$, the $85^{\text {th }}$ percentile of the Comprehensive 6 reference for $\mathrm{WC}$, as well as the $85^{\text {th }}$ percentile for $\% \mathrm{BF}^{(59)}$. Previous analyses have found $\mathrm{WC} \mathrm{z}$ 7 scores to be highly related to BMI z-scores within these Maya children ${ }^{(60)}$.

$9 \quad$ Bioelectrical impedance analysis

10 To calculate percentage body fat, indigenous North American specific equations were used for

11 children (Equation 1) ${ }^{(61)}$ and mothers (Equation 2) ${ }^{(62)}$. These equations were chosen because no

12 validated body composition equations have been created for Mesoamerican indigenous groups

13 such as the Maya.

15 Equation 1: Child's percentage body fat $=-0.49$ (age) +0.51 (sex) +0.44 (weight) +1.55

16 (triceps skinfold) +0.15 (subscapular skinfold) +0.54 ( stature $^{2} /$ resistance) +0.13 (reactance) -

$17 \quad 0.04$ (triceps skinfold $\mathrm{x}$ stature $^{2} /$ resistance) -10.91

18 Where sex is coded 0 for boys, 1 for girls; age is in years, weight is in kilograms; skinfold thickness is in 19 millimeters, resistance and reactance is in Ohms and stature is in meters.

21 Equation 2: Women's fat free mass $=0.001254\left(\right.$ stature $\left.^{2}\right)-0.04904$ (reactance $)+0.1555$

22 (weight) +0.1417 (impedance) -0.0833 (age) +20.05

23 Where stature is in centimeters, weight is in kilograms and reactance and impedance are in Ohms.

25 Fat free mass was transformed into \%BF by subtracting fat free mass from weight and dividing 26 the resulting number by weight and multiplying by 100. [(weight - FFM) / weight] x 100 . 
3 Socioeconomic status and sanitation variables were used to construct two indices. The

4 socioeconomic status index used information on consumer durable goods ownership while the 5 sanitation index used drinking water and toilet facilities. The indices were created by summing

6 affirmative responses to the questions. Each affirmative response (e.g. owning a radio or having

7 a flush toilet) was coded as 1 while negative responses were coded as 0. Families that drank

8 either purchased purified water or cleaned the water were classified as having clean drinking 9 water.

$\underline{\text { Statistical analysis }}$

12 All variables were checked for normality using the Kolmogorov-Smirnov test and skewness and 13 kurtosis z-statistics. Independent $t$-tests were used to check for differences in anthropometry and 14 body composition between the sexes. Pearson chi squares were used to determine if significant 15 differences existed in ownership of any consumer durable good and sanitation measure between 16 households with a stunted and non-stunted mother and with a normal weight and OW/OB child.

17 Stepwise multiple linear regressions using the enter method were used to test the hypothesis that 18 child adiposity is predicted by their mother's chronic early life conditions. The dependent 19 variables were child's adiposity indicators, namely, BMI z-score, \%BF and WC z-scores. BMI zscore is widely used as a proxy for total body adiposity but is a very crude measurement.

21 Therefore we also used \%BF as a measure for total body adiposity. WC z-score is used as an 22 indicator of abdominal adiposity, an independent measure of risk for non-communicable, chronic 23 diseases.

24 The predictors were entered in two steps to determine whether each type of indicator mediated or 25 attenuated the relationship of maternal stature on child's adiposity indicators. The steps were: 1) 26 maternal stature, 2) child's environmental exposures (sanitation index, maternal parity).

27 Maternal stature was used as an indicator of maternal early life environment. The co-variates in 28 the multiple linear regression models were selected to control for the children’s own 
environmental exposures. Ideally, children's stature z-scores would be used as an indicator of their chronic nutritional environment, but there was significant correlation between child and maternal height $(\mathrm{R}=0.440, p=0.001)$ violating the statistical assumption of independence of predictors. Therefore indicators of the child's chronic environment (household sanitation index and maternal parity) were included as predictors. Maternal parity was not linearly related to indicators of child's adiposity and therefore parity was split into tertiles and entered into the model using dummy variables with the tertile associated with the lowest adiposity indicators used as the reference. The commonly used consumer durable goods ownership index was collinear with both sanitation index and maternal parity, and not a significant predictor of child's adiposity, therefore was not included in the multiple regression analyses.

The sexes are combined in the multiple regression analysis because no significant differences were found between them in preliminary analysis. For the analysis with \%BF as the dependent variable, age and sex were included in every model because reference charts were not available for this age group.

The total sample size available for this analysis was 57 mother-child pairs. The power for a multiple linear regression with four predictors with an alpha of 0.8 and a $p$ value of 0.05 has the power to detect an effect size of 0.23 , a medium effect ${ }^{(63)}$.

All analyses were performed using IBM SPSS 19.0. Significance was set a priori at $p<0.05$.

\section{Results}

One mother-child dyad was excluded because the child was developmentally delayed, likely due to being born extremely premature (at 28 weeks), weighing one kilogram at birth. The final sample size was 57 dyads (30 boys).

These Maya children were short (more than one standard deviation below the reference median) and light but had adiposity indicators whose means were above the reference median (Table 1). No sex differences in the children's anthropometry were found. Mothers were short (mean stature $147 \mathrm{~cm}$ ) with 44 (77.2\%) being classified as stunted. Mothers were also heavy, with high mean BMI value (30) and high adiposity as indicated by their WC (88 cm) and \% BF (42\%). 
4 Socio-demographic characteristics are as follows: In terms of sanitation, over three quarters of

5 families drank purified, cleaned water while under two thirds had a flush toilet in the house,

6 bringing the mean additive index score to 1.39 ( $\mathrm{SD}=0.73$ ). Maternal parity was on average 3.25

7 children ( $\mathrm{SD}=1.38)$, with a range of 1-8. The majority of the mothers had two (22\%) or three

8 (48\%) children. The mean child birth weight reported by the mothers was 3.08 kilograms (SD= 9 0.54).

10 In the multiple linear regression analyses, maternal height was neither a significant predictor of

11 nor explained any variance in any measure of child's adiposity (Tables 2-4). Also, the household

12 sanitation index was not a significant predictor of any measure of child's adiposity. Maternal

13 parity was a significant predictor of \%BF (Table 4) but not of child’s BMI z-scores (Table 2) or

14 WC z-score (Table 3). Children with fewer siblings had significantly higher \%BF than those

15 with more siblings with the significant differences occurring between the children whose

16 mothers had 1-2 children versus 3-8 children, explaining 5.6\% of the variance in child's \%BF.

17
***Table 2 about here ${ }^{* * *}$

***Table 3 about here***

***Table 4 about here ${ }^{* * *}$

4 Discussion

This study finds no support, within this sample of urban Maya, for the hypothesis that maternal stature is a significant predictor of her child's fatness, whether fatness is assessed either 
by BMI z-scores, \%BF, or WC z-scores. There are several possible reasons for this. It is possible

2 that there is a predictive relationship but our sample size is too small for sufficient statistical power. Modest sample size is a limitation, but our power analysis indicates we should be able to detect a moderate effect. It is possible that children aged 7-9 years are too young to show the intergenerational effect of mother's height on child fatness. We consider this unlikely because by age 7 years patterns of growth are usually well established ${ }^{(37)}$ and relative fatness at age 7-9 years has a reasonably high predictive association with fatness later in life ${ }^{(64,65)}$. Another

8 possibility is that there may not be enough variation in maternal height to find a significant relationship with child fatness. Any consideration of Maya growth and nutritional status must begin with an understanding that Maya adults are the shortest people in the contemporary world $^{(39)}$. This statement excludes the Central African Pygmies and Philippine Pygmies, whose short average stature is due to some combination of genome mutations, hormonal insufficiencies, missing carrier proteins for hormones, and other neuroendocrine pathology. None of these causes for short stature are known to afflict the Maya. Not only is their average stature very short, but the entire range of height of the adult Maya population is shifted downward and restricted to a relatively narrow range (Bogin, unpublished analysis). The range restriction may reduce height variability to the point that it violates the normality requirements for statistical analysis.

In terms of public health measures to decrease childhood obesity rates, it is encouraging that there does not seem to be a significant intergenerational effect of maternal stature on childhood obesity. If true, reducing childhood obesity rates may not lag a generation and can be relatively quickly reversed once an effective intervention is developed and implemented for transitioning populations. Public health interventions are more likely to be funded and supported, particularly by governments, if the benefits are seen quickly. Since the challenges of addressing malnutrition (both under- and over-nutrition) are substantial, a lack of a prolonged intergenerational influence is advantageous for public health programs.

However, there is evidence in this study that socioeconomic variables predict high levels of fatness among the children. The Maya of Mexico and Central America have been, historically, very short due to the synergism of nutritional deficiencies, infectious diseases (including parasites) and a legacy of political oppression, war and social instability. The rapidity of the nutrition transition in Mexico has created different environments for growth for the Maya mothers and their children. The Maya mothers in our sample are characterized as nutritional 
dual-burdened, being both stunted and overweight ${ }^{(42)}$. Before the $21^{\text {st }}$ Century, Maya in Mexico

2 and Guatemala were characterized as stunted and thin ${ }^{(44,64)}$ and this was the nutritional situation

3 for the mothers when they were children themselves. Recently, the nutrition transition brought

4 about a steep increase in the consumption of high-fat, high caloric foods and snacks ${ }^{(43,44,66,67)}$.

$5 \quad$ Food frequency surveys in Yucatan carried out since the year 2000 found that tortillas

6 and beans remain staples of the diet, but are now purchased as industrially prepared products ${ }^{(68)}$.

7 Store bought tortillas may have a lower content of vitamins and minerals, such as calcium. A

8 study of food consumption patterns in two rural Yucatec Maya villages found that $65 \%$ of

9 households were medium consumers of industrialized foods (up to 33\% of all foods consumed)

10 and $11 \%$ of families were heavy consumers (up to $53 \%$ of all foods eaten were industrialized) ${ }^{(68)}$.

11 Our ethnographic observations found that the urban Maya of Merida do not practice subsistence

12 farming and rarely have any vegetable garden. Several families had one or two fruit trees on their

13 property (mostly lime trees). The ubiquity and very high intake of sugary drinks led one research

14 team to proclaim that the Yucatan of Mexico has been 'coca-colonized ${ }^{\text {,(43) }}$.

In the multiple regression analysis of this study, maternal parity significantly and positively predicted child's adiposity, so that children from families with four or more children

17 had higher adiposity than those from smaller families. Household size has been linked to 18 household dual burden in other transitioning populations ${ }^{(69)}$. Within the context of stunting it seems counter-intuitive that larger families have children with more adiposity. Yet this is a transitioning, dual burdened sample and as such, traditional relationships between poverty and malnutrition do not necessarily hold. These Maya families may have transitioned to the stage where their relationship with resource access/ distribution and adiposity is more similar to communities of low SES in the higher income countries. Within higher income countries, larger families of lower SES have been found to have increased obesity ${ }^{(70)}$. Some have linked the stress associated with food insecurity and poverty to resource distribution and parental behaviours which may lead to child overweight ${ }^{(71,72)}$. In such contexts, families with more children may

27 prioritize cheap food that has high caloric density but is also highly processed and thereby offering little in terms of other nutrients ${ }^{(70,72,73)}$.

The results from this analysis suggest that high levels of child adiposity may be reversed without a generational lag provided that effective obesity prevention measures can be developed and implemented in a timely manner. To be effective, such measures require political will and 
must target the underlying issues, such as poverty, in order to improve the nutritional status and health of the population.

\section{References}

1. Popkin BM (2002) The shift in stages of the nutrition transition in the developing world differs from past experiences! Public Health Nutr 5, 205-214.

2. Alves JG, Falcao RW, Pinto RA et al. (2011) Obesity patterns among women in a slum area in Brazil. J Health Popul Nutr 29, 286-289.

3. Ferreira HS, Moura FA, Cabral CR, Jr. et al. (2009) Short stature of mothers from an area endemic for undernutrition is associated with obesity, hypertension and stunted children: a population-based study in the semi-arid region of Alagoas, Northeast Brazil. Br J Nutr 101, 1239-1245.

4. Florencio TT, Ferreira HS, Cavalcante JC et al. (2003) Food consumed does not account for the higher prevalence of obesity among stunted adults in a very-low-income population in the Northeast of Brazil (Maceio, Alagoas). Eur J Clin Nutr 57, 1437-1446.

5. Florencio TT, Ferreira HS, Cavalcante JC et al (2007) Short stature, abdominal obesity, insulin resistance and alterations in lipid profile in very low-income women living in Maceio, north eastern Brazil. Eur J Cardiov Prev R 14. 346-348.

6. Grillo LP, Siqueira AF, Silva AC et al. (2005) Lower resting metabolic rate and higher velocity of weight gain in a prospective study of stunted vs nonstunted girls living in the shantytown of Sao Paulo, Brazil. Eur J Clin Nutr 59, 835-842.

7. Martins PA, Hoffman DJ, Fernandes MT et al. (2004) Stunted children gain less lean body mass and more fat mass than their non-stunted counterparts: a prospective study. $\mathrm{Br} J \mathrm{Nutr}$ 92, 819-825.

8. Romaguera D, Samman N, Farfan N et al. (2008) Nutritional status of the Andean population of Puna and Quebrada of Humahuaca, Jujuy, Argentina. Pub Health Nutr 11, 606-615.

9. Said-Mohamed R, Allirot X, Sobgui M et al. (2009) Determinant of overweight associated with stunting in preschool children of Yaounde, Cameroon. Ann Hum Biol 36, 146-161.

10. Sichieri R, Dos Santos Barbosa F, Moura EC (2010) Relationship between short stature and obesity in Brazil: a multilevel analysis. Br J Nutr 103, 1534-1538.

11. Frisancho AR (2003) Reduced rate of fat oxidation: a metabolic pathway to obesity in the developing nations. Am J Hum Biol 15, 522-532.

12. Said-Mohamed R, Bernard JY, Ndzana AC et al. (2012) Is overweight in stunted preschool children in Cameroon related to reductions in fat oxidation, resting energy expenditure and physical activity? Plos One 7, e39007.

13. Soares-Wynter SY, Walker SP (1996) Resting metabolic rate and body composition in stunted and nonstunted children. Am J Clin Nutr 64, 137-141.

14. Hoffman DJ, Roberts SB, Verreschi I et al. (2000) Regulation of energy intake may be impaired in nutritionally stunted children from the shantytowns of Sao Paulo, Brazil. J Nutr 130, 2265-2270.

15. Spurr GB, Reina JC (1988) Patterns of daily energy expenditure in normal and marginally undernourished school-aged Colombian children. Eur J Clin Nutr 42, 819-834. 
16. Wilson HJ, Dickinson F, Hoffman DJ et al. (2012) Fat free mass explains the relationship between stunting and energy expenditure in urban Mexican Maya children. Ann Hum Biol 39, 432-439.

17. Emanuel I (1986) Maternal health during childhood and later reproductive performance. Ann $N$ Y Acad Sci 477, 27-39.

18. Drake AJ, Walker BR (2004) The intergenerational effects of fetal programming: nongenomic mechanisms for the inheritance of low birth weight and cardiovascular risk. $J$ Endocrinol 180, 1-16.

19. Gluckman PD, Hanson MA (2004) The developmental origins of the metabolic syndrome. Trends Endocrinol Metab 15, 183-187.

20. Kuzawa CW (2005) Fetal origins of developmental plasticity: are fetal cues reliable predictors of future nutritional environments? Am J Hum Biol 17, 5-21.

21. Wells JC (2010) Maternal capital and the metabolic ghetto: An evolutionary perspective on the transgenerational basis of health inequalities. Am J Hum Biol 22, 1-17.

22. Patti ME (2013) Intergenerational programming of metabolic disease: evidence from human populations and experimental animal models. Cell Mol Life Sci 70, 1597-1608.

23. Benyshek DC, Johnston CS, Martin JF (2006) Glucose metabolism is altered in the adequately-nourished grand-offspring (F3 generation) of rats malnourished during gestation and perinatal life. Diabetologia 49, 1117-1119.

24. Bertram C, Khan O, Ohri S et al. (2008) Transgenerational effects of prenatal nutrient restriction on cardiovascular and hypothalamic-pituitary-adrenal function. J Physiol 586, 2217-2229.

25. Jimenez-Chillaron JC, Isganaitis E, Charalambous M et al. (2009) Intergenerational transmission of glucose intolerance and obesity by in utero undernutrition in mice. Diabetes 58, 460-468.

26. Painter RC, Osmond C, Gluckman P et al. (2008) Transgenerational effects of prenatal exposure to the Dutch famine on neonatal adiposity and health in later life. BJOG 115, 12431249.

27. WHO (2005) Health and the Millennium Development Goals. Geneva, Switzerland: World Health Organization.

28. Kuzawa CW, Sweet E (2009) Epigenetics and the embodiment of race: developmental origins of US racial disparities in cardiovascular health. Am J Hum Biol 21, 2-15.

29. Flegal KM, Carroll MD, Kit BK et al. (2012) Prevalence of obesity and trends in the distribution of body mass index among US adults, 1999-2010. JAMA 307, 491-497.

30. James WP, Rigby N, Leach R (2006) Obesity and the metabolic syndrome: the stress on society. Ann N Y Acad Sci 1083, 1-10.

31. Ogden CL, Yanovski SZ, Carroll MD et al. (2007) The epidemiology of obesity. Gastroenterology 132, 2087-2102.

32. Stein AD, Wang M, Martorell R et al. (2007) Growth patterns in early childhood and final attained stature: data from five birth cohorts from low- and middle-income countries. Am J Hum Biol 22, 353-359.

33. Bogin B, Keep R (1999) Eight thousand years of economic and political history in Latin America revealed by anthropometry. Ann Hum Biol 26, 333-351.

34. Drake AJ, Liu L (2010) Intergenerational transmission of programmed effects: public health consequences. Trends Endocrin Met 21, 206-213. 
35. Pembrey ME, Bygren LO, Kaati G et al. (2006) Sex-specific, male-line transgenerational responses in humans. Eur J Hum Genet 14, 159-166.

36. Skinner MK, Manikkam M, Guerrero-Bosagana C (2010) Epigenetic transgenerational actions of environmental factors in disease etiology. Trends Endocrin Met 21, 214-222.

37. Cameron N (2002) Human growth curve, canalization, and catch-up growth. In Human growth and development, pp. 1-20 [N Cameron, editor]. Amsterdam: Academic Publishers.

38. Cameron N, Demerath EW (2002) Critical periods in human growth and their relationship to diseases of aging. Am J Phys Anthropol Supp 35, 159-184.

39. Bogin B (2012) The Maya in Disneyland: Child Growth as a Marker of Nutritional, Economic, and Political Ecology. In Nutritional Anthropology: Biocultural Perspectives on Food and Nutrition, $2^{\text {nd }}$ ed., pp. 231-244 [DL Dufour, A Goodman and GH Pelto, editors]. Oxford: Oxford University Press.

40. Bracamonte P (2007) Una deuda historica. Ensayo sobre las causas de pobreza secular d los mayos yucatecos. Mexico, D. F.: CIESAS-Porrua-ICY.

41. Azcorra H, Dickinson F, Rothenberg SJ (2009) Family migration and physical growth in Merida, Yucatan, Mexico. Am J Hum Biol 21, 398-400.

42. Varela-Silva MI, Dickinson F, Wilson H et al. (2012) The nutritional dual-burden in developing countries- how is it assessed and what are the health implications? Collegium Antropol 36, 39-45.

43. Leatherman TL, Goodman A (2005) Coca-colonization of diets in the Yucatan. Soc Sci Med 61, 833-846.

44. Leatherman, Goodman AH, Stillman T (2010) Changes in stature, weight, and nutritional status with tourism based economic development in the Yucatan. Econ Hum Biol 8, 153-158.

45. Rivera JA, Barquera S, Campirano F et al. (2002) Epidemiological and nutritional transition in Mexico: rapid increase of non-communicable chronic diseases and obesity. Public Health Nutr 5, 113-122.

46. Rivera JA, Barquera S, Gonzalez-Cossio T et al. (2004) Nutrition transition in Mexico and in other Latin American countries. Nutr Rev 62, S149-157.

47. Azcorra H, Varela-Silva MI, Rodriguez L et al. (2013) Nutritional status of Maya children, their mothers, and their grandmothers residing in the city of Merida, Mexico: Revisiting the leg-length hypothesis. Am J Hum Biol 23, 398-400.

48. Dickinson F, Garcia A, Perez S (1999) Social differentiation and urban segregation in a Mexican regional metropolis. In Problems of megacities: social inequalities, environmental risk and urban governance, pp. 345-358 [A Guillermo Aguilar and I Escamilla, editors]. Mexico, D. F.” Universidad Nacional Autonoma de Mexico.

49. Fuentes JH (2005) Espacios, actors, practicas e imaginarios urbanos en Merida, Yucatan, Mexico. Merida, Mexico: Universidad Autonoma de Yucatan.

50. Frenk J (2006) Bridging the divide: global lessons from evidence-based health policy in Mexico. Lancet 368, 954-961.

51. Frenk J, Gonzalez-Pier E, Gomez-Dantes O et al. (2006) Comprehensive reform to improve health system performance in Mexico. Lancet 368, 1524-1534.

52. World Bank (2010) http://data.worldbank.org/country/mexico. (accessed 13 October 2011).

53. UNICEF (2011) Millennium Development Goals. http://www.unicef.org.mdg/. (accessed 5 December 2011).

54. Lohman TG, Roche AF, Martorell R (1988) Anthropometric standardization reference manual. Champaign, IL: Human Kinetics Books. 
55. DHS (1989) Mexico: encuesta nacional sobre fecundidad y salud 1987. Demographic and Health Survey. Mexico, D. F.: Institute for Resource Development/ Macro Systems, Inc, Columbia, Maryland, USA.

56. Frisancho AR (2008) Anthropometric standards: an interactive nutritional reference of body size and body composition for children and adults. Ann Arbor, Michigan: University of Michigan Press.

57. Lara-Esqueda A, Aguilar-Salinas CA, Velazquez-Monroy O et al. (2004) The body mass index is a less-sensitive tool for detecting cases of obesity-associated co-morbidities in short stature subjects. Int J Obes Relat Metab Disord 28, 1443-1450.

58. Cole TJ, Bellizzi MC, Flegal KM et al. (2000) Establishing a standard definition for child overweight and obesity worldwide: international survey. BMJ 320, 1240-1243.

59. McCarthy HD, Cole TJ, Fry T et al. (2006) Body fat reference curves for children. In J Obes 30, 598-602.

60. Wilson HJ, Dickinson F, Griffiths PL et al. (2011) How useful is BMI in predicting adiposity indicators in a sample of Maya children and women with high levels of stunting? Am J Hum Biol 23, 780-789.

61. Lohman TG, Caballero B, Himes HJ et al. (1999) Body composition assessment in American Indian children. Am J Clin Nutr 69, 764S-766S.

62. Stolarczyk LM, heyward VH, Hicks VL et al. (1994) Predictive accuracy of bioelectrical impedance in estimating body composition of Native American woman. Am J Clin Nutr 59, 964-970.

63. Cohen J (1992) A power primer. Psychol Bull 112, 155-159.

64. Bogin B (1999) Patterns of Human Growth. $2^{\text {nd }}$ ed. Cambridge: Cambridge University Press.

65. Roche AF (1992) Growth, Maturation and Body Composition: The Fels Longitudinal Study 1929-1991. Cambridge, UK: Cambridge University Press.

66. Gurri FD, Pereira GB, Moran EF (2001) Well-being changes in response to 30 years of regional integration in Maya populations from Yucatan, Mexico. Am J Hum Biol 13, 590602.

67. Gurri FD, Balam G (1992) Regional integration and changes in nutritional status in the central region of Yucatan, Mexico: A study of dental enamel hypoplasia and anthropometry. J Hum Ecol 3, 417-432.

68. Izquierdo OP, Beutelspacher AN, Izaba BS et al. (2012) Frecuencia del consume de alimentos industrializados modernos en la dieta habitual de comunidades mayas de Yucatan, Mexico. Estudios Sociales 20, 155-184.

69. Oddo VM, Rah HJ, Semba RD et al. (2012) Predictors of maternal and child double burden of malnutrition in rural Indonesia and Bangladesh. Am J Clin Nutr 95, 951-958.

70. Drewnowski A, Specter SE (2004) Poverty and obesity: the role of energy density and energy costs. Am J Clin Nutr 79, 6-16.

71. McCurdy K, Gorman KS (2010) Measuring family food environments in diverse families with young children. Appetite 54, 615-618.

72. Beydoun MA, Wang Y (2008) How do socio-economic status, perceived economic barriers and nutritional benefits affect quality of dietary intake among US adults? Eur J Clin Nutr 62, 303-313.

73. Darmon N, Drewnowski A (2008) Does social class predict diet quality? Am J Clin Nutr 87, 1107-1117. 
4 Table 1: Anthropometric variables for urban Yucatec Maya children and mothers*

\begin{tabular}{|c|c|c|c|c|c|c|c|c|}
\hline & \multicolumn{6}{|c|}{ Children } & \multirow{2}{*}{\multicolumn{2}{|c|}{ Mothers }} \\
\hline & \multicolumn{2}{|c|}{ Boys } & \multicolumn{2}{|c|}{ Girls } & \multicolumn{2}{|c|}{ All } & & \\
\hline & Mean & $\mathrm{SD}$ & Mean & SD & Mean & $\mathrm{SD}$ & Mean & $\mathrm{SD}$ \\
\hline N (\%) & 30 & 52.6 & 27 & 47.4 & 57 & 100 & 57 & 100 \\
\hline Age (yrs) & 8.33 & 0.82 & 8.56 & 0.72 & 8.44 & 0.78 & 34.28 & 6.33 \\
\hline Height (cm) & 122.23 & 5.62 & 122.47 & 7.80 & 122.34 & 6.68 & 146.84 & 4.58 \\
\hline Height z-score ${ }^{1}$ & -1.09 & 0.85 & -1.19 & 0.88 & -1.13 & 0.86 & -2.20 & 0.73 \\
\hline Weight (kg) & 26.10 & 4.51 & 28.16 & 7.86 & 27.07 & 6.35 & 63.69 & 10.06 \\
\hline Weight z-score $^{1}$ & -0.59 & 0.78 & -0.22 & 0.91 & -0.42 & 0.86 & -0.08 & 0.63 \\
\hline BMI & 17.38 & 2.20 & 18.50 & 3.69 & 17.91 & 3.02 & 29.52 & 4.21 \\
\hline BMI z-score $^{1}$ & 0.54 & 0.83 & 0.64 & 1.02 & 0.58 & 0.92 & 1.59 & 1.33 \\
\hline $\begin{array}{l}\text { Waist } \\
\text { circumference }^{2}(\mathrm{~cm})\end{array}$ & 58.85 & 5.64 & 61.23 & 9.46 & 59.98 & 7.71 & 88.46 & 9.05 \\
\hline $\begin{array}{l}\text { Waist circumference } \\
\text { z-score }^{1}\end{array}$ & 0.18 & 0.68 & 0.57 & 0.82 & 0.37 & 0.77 & 0.30 & 0.58 \\
\hline Percent body fat ${ }^{3,4,5}$ & 26.84 & 6.22 & 30.01 & 7.18 & 28.40 & 6.81 & 42.28 & 4.28 \\
\hline
\end{tabular}

${ }^{1}$ Age and sex specific z-scores created using the Comprehensive reference ${ }^{(55)}$

${ }^{2}$ One mother excluded from waist circumference measurements due to pregnancy, $n=56$

${ }^{3}$ Children's percent body fat calculated using an indigenous North American equation ${ }^{(60)}$

${ }^{4}$ Women's percent body fat calculated using an indigenous North American women equation ${ }^{(61)}$

${ }^{5}$ Missing data for mothers' \%BF, this analysis $\mathrm{n}=54$

*No significant difference found between the sexes using an independent $t$-test, $p<0.05$

Table 2: Influence of maternal height on children's body mass index zscores in urban Yucatec Mayans using multiple linear regression*

\begin{tabular}{|c|c|c|c|c|c|c|c|}
\hline & \multicolumn{3}{|c|}{ Model 1} & \multicolumn{3}{|c|}{ Model 2} \\
\hline & & B & SE & $\mathbf{P}$ & B & SE & $\mathbf{P}$ \\
\hline Constant & & 1.720 & 3.995 & 0.669 & 1.110 & 4.224 & 0.794 \\
\hline \multirow{2}{*}{\multicolumn{2}{|c|}{$\begin{array}{l}\text { Maternal height (cm) } \\
\text { Sanitation index }\end{array}$}} & -0.008 & 0.027 & 0.771 & -0.004 & 0.029 & 0.894 \\
\hline & & & & & -0.096 & 0.188 & 0.613 \\
\hline \multirow{2}{*}{$\begin{array}{l}\text { Maternal } \\
\text { parity }^{1}\end{array}$} & 3-8 v. 1-2 & & & & 0.304 & 0.358 & 0.399 \\
\hline & $1-2,4-8$ v. 3 & & & & 0.151 & 0.322 & 0.641 \\
\hline \multicolumn{2}{|l|}{$\mathbf{R}^{2}$ adj } & \multicolumn{3}{|c|}{-0.017} & \multicolumn{3}{|c|}{-0.058} \\
\hline
\end{tabular}

\footnotetext{
${ }^{1}$ The highest tertile (4-8 children) set as the reference

* Model 1 tests for intergenerational influences of maternal chronic early life environment. Model 2 controls for the child's own environmental exposures.
} 
1 Table 3: Influence of maternal height on children's waist circumference

2 z-scores in urban Yucatec Mayans using multiple linear regression*

\begin{tabular}{|c|c|c|c|c|c|c|c|}
\hline & \multicolumn{3}{|c|}{ Model 1} & \multicolumn{3}{|c|}{ Model 2} \\
\hline & & B & SE & $\mathbf{p}$ & B & SE & $\mathbf{P}$ \\
\hline Constant & & 0.538 & 3.291 & 0.871 & 0.635 & 3.436 & 0.854 \\
\hline \multirow{2}{*}{\multicolumn{2}{|c|}{$\begin{array}{l}\text { Maternal height }(\mathrm{cm}) \\
\text { Sanitation index }\end{array}$}} & -0.001 & 0.022 & 0.950 & -0.004 & 0.024 & 0.872 \\
\hline & & & & & 0.028 & 0.153 & 0.853 \\
\hline \multirow{3}{*}{$\begin{array}{l}\text { Maternal } \\
\text { parity }^{1}\end{array}$} & $3-8$ v. $1-2$ & & & & 0.426 & 0.291 & 0.150 \\
\hline & $1-2,4-8$ v. 3 & & & & 0.233 & 0.262 & 0.378 \\
\hline & $\mathbf{R}^{2}$ adj & \multicolumn{3}{|c|}{-0.019} & & \multicolumn{2}{|c|}{-0.034} \\
\hline
\end{tabular}

${ }^{1}$ The highest tertile (4-8 children) set as the reference

* Model 1 tests for intergenerational influences of maternal chronic early life

environment. Model 2 controls for the child's own environmental exposures.

9 Table 4: Influence of maternal height on children's percentage body fat in 10 urban Yucatec Mayans using multiple linear regression*

\begin{tabular}{|c|c|c|c|c|c|c|c|}
\hline & \multicolumn{3}{|c|}{ Model 1} & \multicolumn{3}{|c|}{ Model 2} \\
\hline & & B & SE & $\mathbf{P}$ & B & SE & $\mathbf{P}$ \\
\hline Constant & & 20.869 & 29.568 & 0.484 & 14.138 & 29.613 & 0.635 \\
\hline \multicolumn{2}{|c|}{ Maternal height (cm) } & -0.019 & 0.193 & 0.922 & -0.016 & 0.195 & 0.937 \\
\hline \multicolumn{2}{|c|}{ Child's age } & 0.782 & 1.153 & 0.500 & 1.270 & 1.133 & 0.268 \\
\hline \multicolumn{2}{|c|}{ Child's sex 1} & 2.329 & 1.792 & 0.200 & 1.770 & 1.786 & 0.327 \\
\hline \multicolumn{2}{|c|}{ Sanitation index } & & & & -0.209 & 1.249 & 0.868 \\
\hline \multirow{2}{*}{$\begin{array}{l}\text { Maternal } \\
\text { parity }^{2}\end{array}$} & $3-8$ v. $1-2$ & & & & 6.230 & 2.423 & 0.013 \\
\hline & $1-2,4-8$ v. 3 & & & & 3.331 & 2.187 & 0.134 \\
\hline \multicolumn{2}{|c|}{$\mathbf{R}^{2}$ adj } & \multicolumn{3}{|c|}{-0.011} & \multicolumn{3}{|c|}{0.056} \\
\hline
\end{tabular}

12 '2 The highest tertile (4-8 children) set as the reference

13 *Model 1 tests for intergenerational influences of maternal chronic early life environment.

14 Model 2 controls for the child's own environmental exposures. 